\title{
Emotional Cognitive Assessment and Enhancement for Mentally Disabled People
}

\author{
https://doi.org/10.3991/ijoe.v15i04.9844 \\ M. Samir Abou El-Seoud( $\left.{ }^{\bowtie}\right)$, Samaa A. Ahmed \\ The British University in Egypt, Egypt \\ Samir.elseoudabue.edu.eg
}

\begin{abstract}
Autism spectrum syndrome well known as autism. Autism was delivered within the 1920 s century especially in 1944 . Autism is described as a development disease that influences the social abilities, nonverbal communication or what's called body language. Human beings with Autism and Asperger's syndrome tends to have high IQ however very low EQ[1]. In addition, person who suffers autism has a tendency to have a specific habitual, aggressive reaction while converting this habitual. The Proposed concept is to develop an algorithm/method for growing emotional intelligence. The goal of the proposed concept is to assist human beings with Autism and Asperger's syndrome that tends to have under common EI to approach normality [2]. The program will use the high IQ of the person to increase his/her EQ. To achieve this it is intended to develop program that refuse any miss behavior, or inappropriate mind-set. The advanced application acts like human, who will no longer accept to be treated in a particular manner. To enhance ones EI, people with autism ought to be taught on:

- A way to cope with people in a manner they would accept.

- The way to apprehend his/her emotion and accept it.

- The way to express their feelings.

The goal of the evolved program is to help autism users be given human beings and be selves ordinary. The program ought to teach person how to make buddies in the real existence.
\end{abstract}

Keywords-Autism, Asparagus Syndrome, EQ, E-therapy.

\section{Introduction}

In 2004, 47,380 Egyptians was recognized to have an intellectual contamination. More than 6 million Egyptians became estimated to suffer an intellectual illness (Egypt records Center - record) [3]. Consistent with NAMI (National alliance on mental illness), one in five adults suffer from intellectual illness in the USA. It means about 43.8 million people suffer an intellectual illness [4] additionally within the united kingdom one in four people has a tendency to have mental problems and approximately $17 \%$ of Scottish women and $14 \%$ of Scottish men suffers a mental illness.[5]. In 2008 Victorian department of fitness funded the smart (self-management and healing technology) studies application [6]. It specializes in E-therapy citing the idea of treatment programs via 
net. Patients, parents and therapists, can use those programs. The E- remedy studies unit installed the countrywide E-remedy Centre (NeTC) in 2008 [7]. Emotional Intelligence EI is defined as the ability to classify, manipulate, and examine ones emotion. There are forms of emotional intelligence. The primary is capability EI (cognitive emotional capacity). The second one is trait EI (trait emotional self-efficiency). The difference between them is, that the primary may be measured and examined and is more related to the cognitive capability [7]. The second one is extra related to how one measure himself, and how capable he/she is in expressing their feelings, dealing with themselves, and others emotions. [8] Human beings with Autism, and Asperger's syndrome tends to have an extreme low average EQ. Which prevents them from dealing with people, making friends, forming a family, and many others. [9]. there are many therapists, institutes, personal schools, that facilitates individuals who be afflicted by mental infection. Within the development countries children and adults with intellectual illness has a tendency to be handled inappropriately. Furthermore, not all mother and father are capable of sending their kids to a private school, college and/or institutes. This is why E-therapy or software program are developed. They are developed to help those who cannot afford a therapist. As autistic patients have a tendency to suffer from high infection with intense response when their everyday routine is changed [10]. Some games where provided for people with autism along with the online game Ron gets dressed, which shows the consumer/affected person that it is fine to change your day by day routine [9]. Furthermore, human beings with autism are described as egocentric. This attitude can be used towards them as they see themselves as the only ones that matter. available software that intend to help disable customers, not directly presents the help and tips for people with intellectual contamination. It indicates them how other everyday human beings behave and act during their each day life [11] [12]. Those pointers help them to speak, make friends, and boom their self-confidence. Furthermore, such guidelines will permit them to participate and have a rule in their society.

\section{Methodologies}

As Mentioned in the above, there is no program yet for people with low EQ, but there is computer games implemented not to increase the EQ but to help the user to cope. On the other hand, some institutions, and researches recommends some methodologies that one can use to increase his/her EI [13]. Also there are websites that provide EQ Test. In this section we will discuss some of the methodologies currently used, suggest an improvement/ integration. Theoretically, there are five important methods to improve your EI [4],

- Focus on your emotions

- Improve your body language skills and recognize that of others

- Exercise empathy

- Practice self-direction

- Increase your social skills.

Professor Emeritus of Psychology at UCLA,Â Albert Merhabian, states that: 
- $55 \%$ of our correspondence is absorbed from non-verbal communication, Such as body language.

- While $38 \%$ is para-etymological (doing with the way that you say something: tone, delays, pace, and so on) and an insignificant $7 \%$ relates to the genuine words talked $[10]$.

To conclude, non-verbal communication is the most capable segment of how we impart [10]. The Methodologies used in computer games are based on normal gaming algorithms [13], that allows the user to see changes, accept its existence, and cope with it [4].

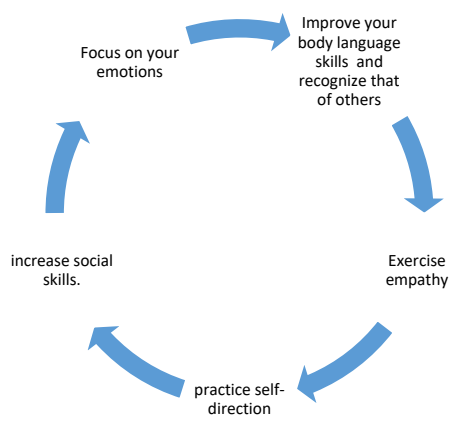

Fig. 1. Five way methodology

\section{Proposed Idea}

The proposed Idea is a program that preforms an EQ test, detecting points of weakness and strength. The above five methodologies in figure 1 will be used to train the user. The developed program provides training on how to act in specific situations. Moreover, the developed program trains the user to learn how to behave, and how to act according to the way the program is repetitively proposing. Thereafter, the program will perform an EQ test repeatedly until the user reaches the normal EQ rates. The goal of this project is to test the Emotional intelligence using EQ tests. The program detect emotions using face detection and check the attitude of user. The program trains the users on how to react in specific conditions. In order to gather measurable information and build up an information base for disable people.

As mentioned above the developed program should:

- Scan the user's face

- Analyse user's emotion

- Recognize user's voice

- Detect user's tune

Here bellow is a sample Pseudo code of the program written in C\# for the interactive dialogue that takes place between the computer and user 


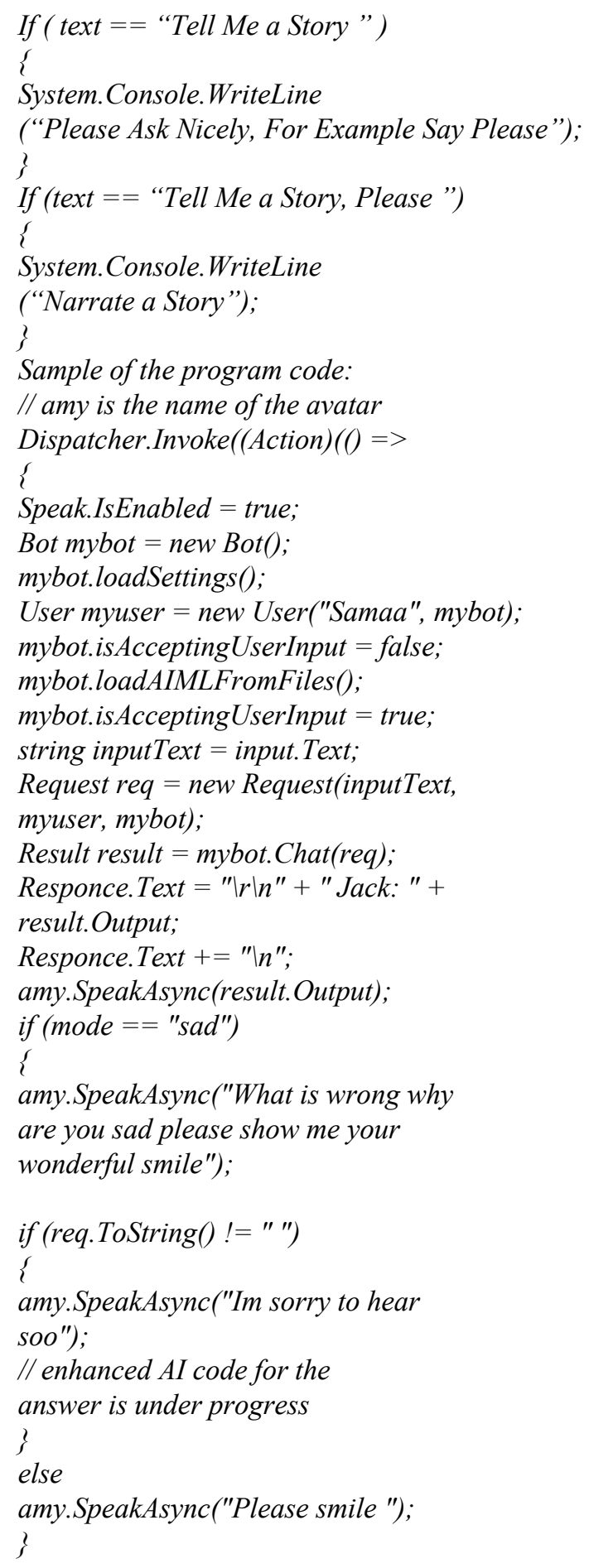




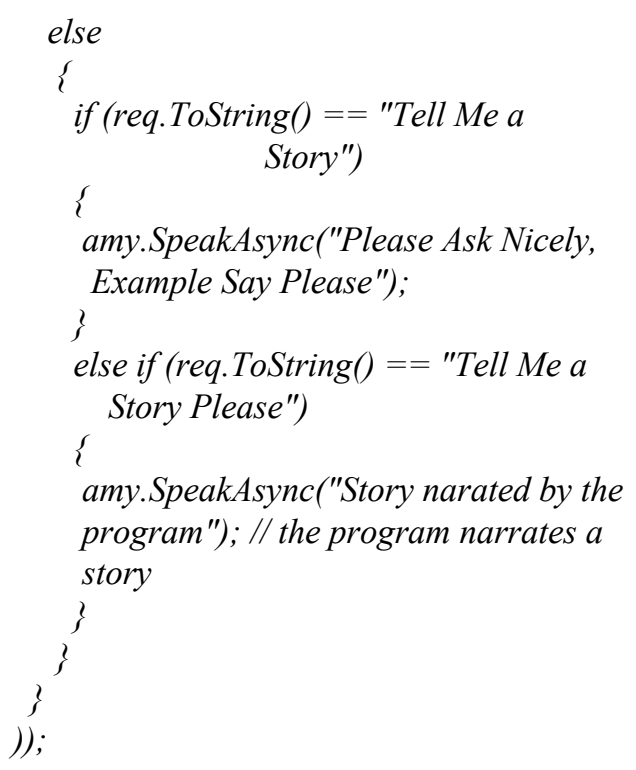

Same will be implemented in Image Detection

If $($ Emotion $==$ 'Sad')

\{

System.Console.WriteLine

("Ask to smile");

\}

If $($ Emotion $==$ 'Smile')

\{

System.Console. WriteLine

("Narrate"); // narrate a story

\}

The program has been divided into the following Tasks:

- Preform an EQ Test: Which can be done by connecting the program to a website that preforms EQ tests. In the meanwhile, a developed program will perform an EQ test.

- Preform Emotion detection: Using Image recognition. This has been achieved using the so-called library Open-CV in Matlab, C\#, python, java.

- Preform sound recognition: This has been done using C\# by Microsoft.net library. One could also use java by sphinx. However, it is preferable to use C\# or python to increase the Efficiency.

- Preform text to speech conversion: This could be performed using C\# or python. Although efficiency in java is higher if Mobrola (a java program application) is used.

- Preform the algorithm: Which uses the above five features appearing in figure 1. This will combine the methodologies appearing in figure1 and the Methodologies 
addressed above for further illustration as an example figure 2 provides an explanation.

Preform an EQ test: Again, to detect the improvement rates and continue on improving till user reaches normal EI rates.

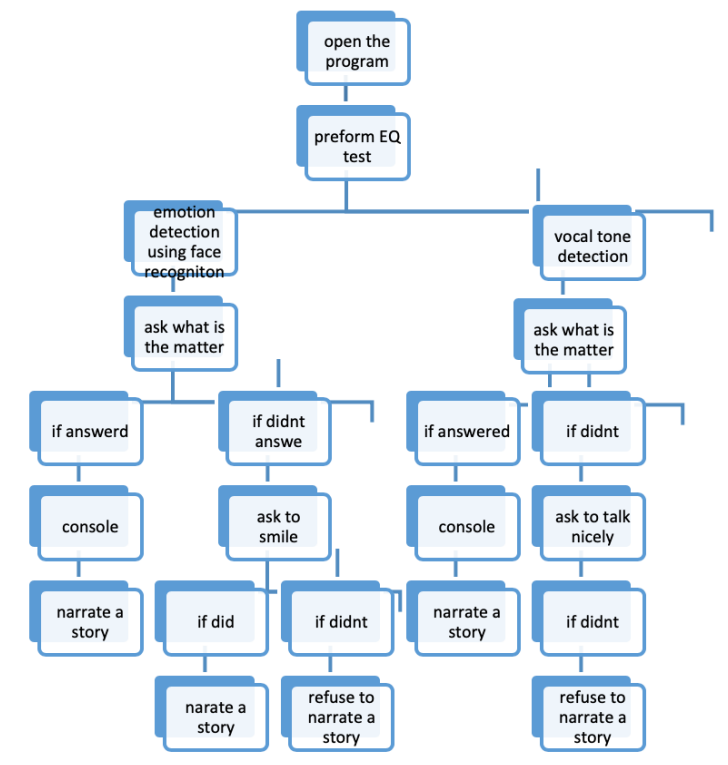

Fig. 2. Algorithm Followed

Here bellow is a brief explanation for the steps illustrated in figure 2 :

- User will open the program

- The user will start dealing with the program

- The user shows an unfriendly attitude

- Program detects what was wrong

- Program asks the user to change attitude

- User changes his attitude

- The program narrates a story regarding the user's misbehavior

- Program will continue dealing with the user first after he changes his attitude.

In point 7 the program reacts like a human. It resamples a situation that the user will face in real life. Therefore, user will learn how to apologize.

The entity "console" in figure 2 means that the program will show empathy for the user. Such kind of empathy could be done using different answers, and machine learning algorithm. Which will check its knowledge base to find a suitable answer, depending on the situation.

Here below are some snapshots previewing the accomplished work (voice recognition and question/answers). The preformed conversation between user and program will be posted on the screen as shown in the snapshots in Figure 3. 

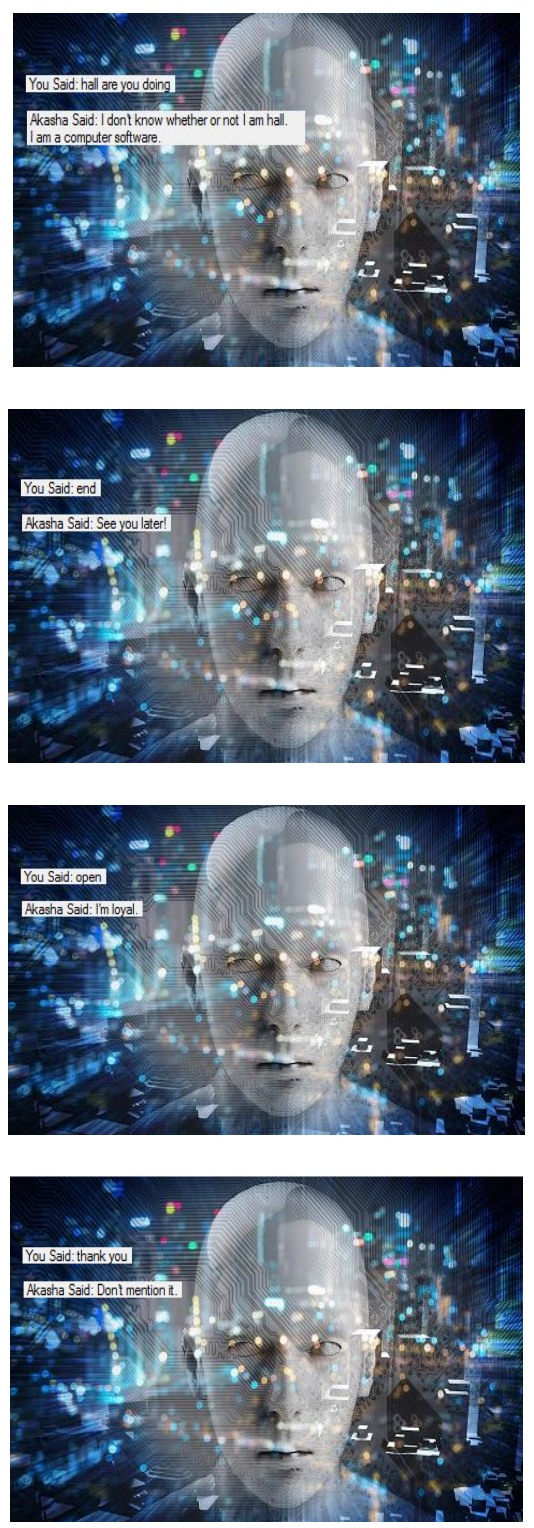

Fig. 3.

The program has been developed using software engineering methodologies which are:

- Designing : Using Class Diagram, Use Case Diagram

- Implementation: Using C\# object oriented language

- Testing: Using negative, positive testing, Developing Test Cases, running test cases manually on the application 
The Data base has been developed by Object oriented data base model which is achieved using db4o library in $\mathrm{CH}$.

Shown below in Fig. 4 are some screen shots from test cases manual execution snap shots.
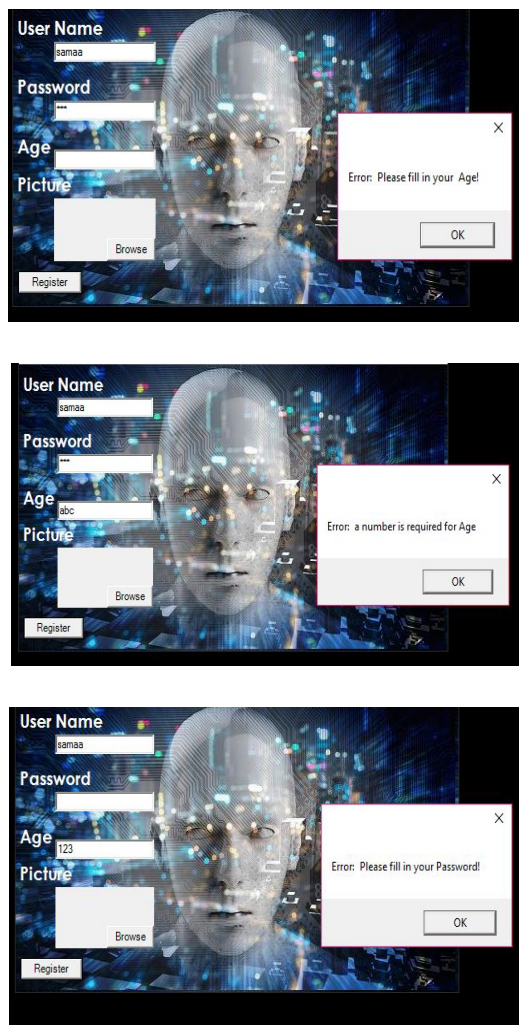

Fig. 4.

\section{Conclusion}

The developed program intend to increase EQ of autism users. The program performs an EQ test repeatedly until the user reaches the normal EI rates. The developed program acts like human during the interaction with the autism user. It will not tolerate the unusual or inappropriate attitude or unacceptable reaction of the user. Moreover, it will try to improve user's reaction by repetitively asked questions until the user's answer is satisfactory. Furthermore, it detects user emotions using face detection and check the user attitude. The program trains the users on how to react in specific conditions. And, the program instructs user on how to make friends in real life. The combination of methodologies and the repetitive EQ tests ensures the effectiveness and efficiency of the product. 


\section{$5 \quad$ References}

[1] Eskridge, R. (n.d.). Using the High IQ of ASD to Foster Emotional Intelligence. Retrieved February 27, 2018. https://aspergers101.com/using-high-iq-asd-foster-emotional-intelligencel

[2] Dr. Poirier, K. (2015, October 12). Teaching Emotional Awareness in Autism. Retrieved January 27, 2018. https://drkarinapoirier.com/teaching-emotional-awarness-in-autism

[3] A Learning Mobile System to Deliver Static and Dynamic Multimedia Tutorials for Children with Disabilities ACase Study: Children with Intellectual Challenges

[4] NAMI. (n.d.). Retrieved February 27, 2018, from https://www.nami.org/Learn-More/Mental-Health-By-the-Numbers

[5] What is eTherapy? (n.d.). Retrieved February 27, 2018, from: http://www.swinburne.edu.au/lss/swinpsyche/etherapy/index.html

[6] FUNDAMENTAL FACTS ABOUT MENTAL HEALTH 2016. (2016). Retrieved February 27, 2018, from https://www.mentalhealth.org.uk/sites/default/files/fundamental-factsabout-mental-health-2016.pdf

[7] Swenson, S. (2012, October 2). Asperger's Syndrome and Emotional Intelligence . Retrieved February 27, 2018, from https://www.goodtherapy.org/blog/aspergers-syndromeemotional-intelligence-1002124

[8] SABRI: The end of autism. (n.d.). Retrieved February 27, 2018, from: http://www.swinburne.edu.au/lss/sabri/index.html

[9] Transactions. (n.d.). Retrieved January 05, 2018, from: $\underline{\text { http://w }}$ ww.autismgames.com.au/game trans.html

[10] Rudacille , D. (2011, September 6). Out of Africa. Retrieved February 27, 2018, from: https://spectrumnews.org/opinion/out-of-africa/

[11] AUTISM AND CHILD DEVELOPMENTAL DISORDERS IN AFRICA. (n.d.). Retrieved February 27, 2018, from www.myaspergers.net/what-is-aspergers/5-steps-to-emotional-intelligence/

[12] Rudacille , D. (2011, September 6). Out of Africa. Retrieved February 27, 2018, from: https://spectrumnews.org/opinion/out-of-africa/

[13] Transactions. (n.d.). Retrieved January 05, 2018, from: http://www.au tismgames.com.au/game trans.html

\section{Authors}

Samaa Amr AbdelAziz Ahmed, born in Cairo Egypt in 1996. Student at the British University in Egypt Faculty of Informatics and Computer Science Department of Software Engineering. Graduate To be in 2018. Free Lancer in Web Development and Web design. Worked in Vodafone International Service As an Advanced Technical Advisor. Research interest is Artificial intelligence and Educational Programs for people with Mental Illness.

Professor Samir Abou El-Seoud received his BSc degree in Physics, Electronics and Mathematics from Cairo University in 1967, his Higher Diplom in Computing from Technical University of Darmstadt (TUD) /Germany in 1975 and his Doctor of Science from the same University (TUD) in 1979. His field of study includes - Scientific Computations and Parallel Algorithms. His Research Interests include -_Computer Aided 
Learning, Parallel Algorithms, Numerical Scientific Computations and Computational Fluid Mechanics

Professor El-Seoud holds different academic positions at TUD Germany. Letest Full-Professor in 1987. Outside Germany Professor El-Seoud spent different years as a Full-Professor of Computer Science at SQU - Oman, Qatar University, and PSUTJordan and acted as a Head of Computer Science for many years. At industrial institutions, Professor El-Seoud worked as Scientific Advisor and Consultant for the GTZ in Germany and was responsible for establishing a postgraduate program leading to M.Sc. degree in Computations at Colombo University / Sri-Lanka (2001 - 2003). He also worked as Application Consultant at Automatic Data Processing Inc., Division Network Services in Frankfurt/Germany (1979 - 1980). Professor El-Seoud joined The British University in Egypt (BUE) in 2012. Currently, he is Basic Science Coordinator at the Faculty of Informatics and Computer Science (ICS) at BUE. Professor El-Seoud has more than 150 publications in international proceedings and international reputable journals.

Article submitted 10 November 2018. Resubmitted 21 December 2018. Final acceptance 07 January 2019. Final version published as submitted by the authors. 